\title{
Does donor arterial partial pressure of oxygen affect outcomes after lung transplantation? A review of more than 12,000 lung transplants
}

\author{
Farhan Zafar, MD, ${ }^{\text {a,b }}$ Muhammad S. Khan, MD, ${ }^{\text {a,b }}$ Jeffrey S. Heinle, MD, ${ }^{\text {a,b }}$ Iki Adachi, MD, ${ }^{\text {a,b }}$ \\ E. Dean McKenzie, MD, ${ }^{\mathrm{a}, \mathrm{b}}$ Marc G. Schecter, MD, ${ }^{\mathrm{c}}$ George B. Mallory, MD, ${ }^{\mathrm{c}}$ and \\ David L. S. Morales, MD ${ }^{a, b}$
}

\begin{abstract}
Introduction: In lung transplantation ( $\mathrm{LTx})$, the arterial partial pressure of oxygen $\left(\mathrm{PaO}_{2}\right)$ is traditionally regarded as critical information for assessment of donor lung function. Each center sets its own thresholds; by convention, a donor $\mathrm{PaO}_{2}$ of less than $300 \mathrm{~mm} \mathrm{Hg}$ has been considered disqualifying. Limited literature exists to support such a practice. We analyzed all LTxs performed in the United States over a 9-year period to assess the effect of donor $\mathrm{PaO}_{2}$ on graft survival.
\end{abstract}

Methods: The United Network for Organ Sharing (UNOS) database was queried for LTx (January 2000November 2009). Of 12,545 LTx performed, 12,045 (96\%) had donor $\mathrm{PaO}_{2}$ data on a fraction of inspired oxygen of 1.0 , recorded at the time of procurement.

Results: Mean donor $\mathrm{PaO}_{2}$ was $407 \pm 140 \mathrm{~mm} \mathrm{Hg}$. The majority of LTxs had a donor $\mathrm{PaO}_{2}$ greater than $300 \mathrm{~mm}$ $\mathrm{Hg}(9593(80 \%])$ whereas $\mathrm{PaO}_{2}$ was $200 \mathrm{~mm} \mathrm{Hg}$ or less in $1830(15 \%)$ and 201 to 300 in $582(5 \%)$ donors. Use of donors with $\mathrm{a} \mathrm{PaO}_{2}$ of less than 200 increased over time from 5\% (45) in 2000 to $21 \%$ (295) in 2009 $(P=.002)$. Kaplan-Meier survival analysis showed no difference in graft survival with differing donor $\mathrm{PaO}_{2} \mathrm{~s}$, irrespective of whether patients had a single or double LTx. A Cox multivariable analysis of 21 donor characteristics demonstrated that donor $\mathrm{PaO}_{2}$ had no association with graft survival.

Conclusions: Donor $\mathrm{PaO}_{2}$ levels did not affect graft survival. The use of donors with lower $\mathrm{PaO}_{2} \mathrm{~S}$ could substantially increase the donor pool. We are not suggesting that donor $\mathrm{PaO}_{2}$ is not important when assessing potential lung donors but its level of importance in regard to other criteria appears less than previously believed. (J Thorac Cardiovasc Surg 2012;143:919-25)

Lung transplantation (LTx), like all solid organ transplantation, is struggling with the demand of donor organs exceeding supply and increasing waitlist mortality. Therefore, attempts to improve the supply of donor lungs by aggressive donor management, ${ }^{1-3}$ use of ex vivo perfusion, use of cardiac death donors, and liberalization of the donor selection criteria $^{4,5}$ are actively being practiced to minimize the widely documented mismatch of demand and supply. ${ }^{6}$

In current practice, arterial partial pressure of oxygen $\left(\mathrm{PaO}_{2}\right)$ is considered critical information for assessment of donor lung function. Standard LTx donor criteria in the

\footnotetext{
From the Michael E. DeBakey Department of Surgery, ${ }^{\text {a }}$ Baylor College of Medicine, Congenital Heart Surgery, ${ }^{\mathrm{b}}$ Texas Children's Hospital, and the Department of Pediatric Pulmonology, ${ }^{\mathrm{c}}$ Baylor College of Medicine and Texas Children's Hospital, Houston, Tex.

Disclosures: Authors have nothing to disclose with regard to commercial support.

Read at the 91st Annual Meeting of The American Association for Thoracic Surgery, Philadelphia, Pennsylvania, May 7-11, 2011.

Received for publication May 11, 2011; accepted for publication Jan 16, 2012; available ahead of print Feb 17, 2012.

Address for reprints: David L. S. Morales, MD, Division of Congenital Heart Surgery, Texas Children's Hospital, 6621 Fannin St, WT19345H, Houston, TX 77030 (E-mail: dlmorale@texaschildrenshospital.org).

0022-5223/ $\$ 36.00$

Copyright (c) 2012 by The American Association for Thoracic Surgery

doi:10.1016/j.jtcvs.2012.01.044
}

literature recommend that the donor $\mathrm{PaO}_{2}$ should be more than $300 \mathrm{~mm} \mathrm{Hg}$ and that use of donor lungs with $\mathrm{PaO}_{2} \mathrm{~s}$ of less than $300 \mathrm{~mm} \mathrm{Hg}$ could be associated with decreased posttransplant pulmonary function. However, no significant evidence is available to support such a practice. ${ }^{7,8}$ As stated in the consensus report from The Pulmonary Council of the International Society of Heart and Lung Transplantation:

The origin of the "standard" arterial blood gas criteria for evaluating the suitability of the potential pulmonary donor is shrouded in the mists of time. In 1987 Harjula et $\mathrm{al}^{9}$ described a single case of perioperative graft failure in which the arterial partial pressure of oxygen $\left(\mathrm{PaO}_{2}\right)$ was $<100 \mathrm{~mm} \mathrm{Hg}$, with a fraction of inspired oxygen $\left(\mathrm{FiO}_{2}\right)$ of 0.4 (ie, $\mathrm{PaO}_{2} / \mathrm{FiO}_{2}$ ratio $<250$ ), and it is likely the acceptability ratio of $300\left(\mathrm{PaO}_{2}\right.$ of $120 \mathrm{~mm} \mathrm{Hg}$ on an $\mathrm{FiO}_{2}$ of $0.4)$ was then arbitrarily chosen to provide a slight margin of safety. It is more puzzling as to why this standard has been so closely adhered to since that report. The literature provides no answers as no studies have addressed this issue specifically.*

\footnotetext{
* Reprinted with permission. ${ }^{8}$
} 


\section{Abbreviations and Acronyms \\ $\mathrm{DCD}=$ donation after cardiac death \\ $\mathrm{FiO}_{2}=$ fraction of inspired oxygen \\ ISHLT $=$ International Society for Heart and Lung Transplantation \\ LTx = lung transplant (transplantation) \\ OPTN $=$ Organ Procurement and Transplant Network \\ $\mathrm{PaO}_{2}=$ arterial partial pressure of oxygen \\ UNOS $=$ United Network for Organ Sharing}

With no strong literature available to validate this common practice, the purpose of this study was to assess specifically the effect of donor $\mathrm{PaO}_{2}$ on graft survival using a large all-inclusive national database.

\section{METHODS}

In November 2009, a retrospective analysis of Organ Procurement and Transplant Network (OPTN) data was performed. The OPTN is the unified transplant network established by the United States Congress under the National Organ Transplant Act of 1984. The United Network for Organ Sharing (UNOS) is a private, nonprofit organization that administers the OPTN under federal contract.

UNOS/OPTN Thoracic database was queried for LTx from January of 2000 through November of 2009. Of the 12,545 LTx operations performed, $12,045(96 \%)$ had donor $\mathrm{PaO}_{2}$ data on a fraction of inspired oxygen $\left(\mathrm{FiO}_{2}\right)$ of 1.0 recorded at the time of procurement. The italicized phrase is how this data point is exactly listed in the UNOS database.

Transplants were divided into groups $\mathrm{A}$ to $\mathrm{D}$ based on donor $\mathrm{PaO}_{2}$ at the time of procurement (A, <200; B, 201-300; C, 301-400; and D, >400 mm $\mathrm{Hg}$ ).

For baseline characteristics, continuous variables were compared using the $t$ test and analysis of variance, with the Tukey method for controlling for multiple comparisons. Categorical variables were compared using the $\chi^{2}$ test. Survival curves were estimated using the Kaplan-Meier method, and equality of survival curves was tested using a log-rank test. Multivariate analyses were performed using Cox proportional hazards regression simultaneous models, in which all 21 donor variables available in the UNOS database were used to test their association with graft survival.

\section{RESULTS}

A total of 12,045 LTXs were analyzed, of which $40.4 \%$ (4864) were performed in female patients. Mean donor age was $32 \pm 15$ years (median, 29 years; range, $0-75$ years). Mean recipient age was $50.7 \pm 14.7$ years (median, 56 years; range, $<1-81$ years). Mean donor $\mathrm{PaO}_{2}$ was $408 \pm$ $140 \mathrm{~mm} \mathrm{Hg}$. The majority of the transplants had a donor $\mathrm{PaO}_{2}$ greater than $400(7756[64.4 \%])$ whereas donor $\mathrm{PaO}_{2}$ was 200 or less in $1830(15.2 \%), 201$ to 300 in 582 $(4.8 \%)$, and 301 to 400 in 1877 (15.6\%). Use of donors with $\mathrm{PaO}_{2}$ less than 200 increased over time from $5 \%$ $(45 / 867)$ in 2000 to $21 \%(295 / 1388)$ in $2009(P=.002)$.

Donor and recipient characteristics in the different donor $\mathrm{PaO}_{2}$ subgroups are listed in Tables 1 and 2. There was no significant difference in length of hospital stay after transplantation $\left(\mathrm{PaO}_{2} \leq 200 \mathrm{~mm} \mathrm{Hg}, 24 \pm 27\right.$ days; 201$300 \mathrm{~mm} \mathrm{Hg}, 25 \pm 33$ days; 301-400 mm Hg, $24 \pm 29$ days, $>400 \mathrm{~mm} \mathrm{Hg}, 24 \pm 30$ days). Kaplan-Meier survival analysis showed no significant differences in graft survival for different donor $\mathrm{PaO}_{2}$ levels (Figure 1, A). When single $(\mathrm{n}=5019)$ and double $(\mathrm{n}=7026)$ LTx recipients were evaluated separately, there remained no significant difference in graft survival for different donor $\mathrm{PaO}_{2}$ levels (Figure 1, B). A Cox proportional multivariate analysis of 21 donor characteristics demonstrated that there was no association of donor $\mathrm{PaO}_{2}$ as a continuous variable to graft survival (Table 3). However, steroid dependence and hypertension appeared to be risk factors associated with poor graft survival.

\section{DISCUSSION}

LTx is an acceptable therapy for patients with end-stage lung disease. However, LTx is limited by an inadequate number of donors, as is common to all other fields of solid organ transplantation. This mismatch results in increasing waitlist time and mortality for LTx with an average waitlist time of 539 days and more than 7000 deaths occurring each year in patients awaiting a lung donor. ${ }^{10}$ Two novel approaches have recently been developed to address this issue and potentially increase the donor pool for LTx. The first approach is donation after cardiac death (DCD). The number of programs using DCD for LTx has increased substantially; the number of DCD lung donors has increased $24 \%$ from 2006 to $2008 .{ }^{11}$ Moreover, many studies have demonstrated comparable if not better outcomes using DCD compared with donation after brain death. ${ }^{12-14} \mathrm{~A}$ second novel approach is a newly developed protective normothermic ex vivo lung perfusion technique used to render suboptimal lungs from a DCD or brain death donor viable for transplantation. This system allows the lungs after procurement to be perfused with an acellular solution for approximately 4 hours so that the lungs can be optimized as well as continually reassessed. Thus injured donor lungs that were initially unsuitable for transplantation may be successfully transplanted. ${ }^{15}$ The first prospective clinical ex vivo perfusion trial, the "Help" trial, was recently completed by the Toronto group. They demonstrated that 23 LTx recipients whose donor lungs underwent ex vivo perfusion had similar early outcomes when compared with conventionally selected and transplanted donor lungs. ${ }^{16}$

In the attempt to increase the donor lung pool, other centers have liberalized their donor criteria, (eg, donor age $>55$ years, smoking $>20$ pack-years, pathology on chest $\mathrm{x}$-ray films, and purulent secretions at bronchoscopy) and have demonstrated that their outcomes did not change. ${ }^{4,5}$ In 2003, the International Society for Heart and Lung Transplantation (ISHLT) consensus group on LTx reported the current accepted "ideal" donor criteria as outlined in Table $4 .{ }^{8}$ Most of the criteria have been analyzed and questioned for significance. ${ }^{17}$ However, 1 criterion that 
TABLE 1. Donor characteristics

\begin{tabular}{|c|c|c|c|c|c|}
\hline Donor $\mathrm{PaO}_{2}(\mathrm{~mm} \mathrm{Hg})$ & $<200(n=1830)$ & $201-300(n=582)$ & $301-400(n=1877)$ & $>400(n=7756)$ & Total $(n=12,045)$ \\
\hline Mean age $(y)$ & $33 \pm 15$ & $31 \pm 14$ & $34 \pm 15$ & $32 \pm 14$ & $32.3 \pm 14.5$ \\
\hline Mean weight (kg) & $74 \pm 17$ & $74 \pm 19$ & $77 \pm 19$ & $72 \pm 17$ & $73 \pm 17.7$ \\
\hline \#1 COD: Head trauma & $\mathbf{5 0} \%(\mathbf{9 1 4})$ & $55 \%(322)$ & $50 \%(944)$ & $53 \%(4117)$ & $52 \%(6297)$ \\
\hline \#2 COD: CVA & $37 \%(670)$ & $32 \%(186)$ & $37 \%(696)$ & $36 \%(2763)$ & $36 \%(4315)$ \\
\hline $\begin{array}{l}\text { History of smoking }(>20 \\
\text { pack-years within recent } 6 \text { mo) }\end{array}$ & $13 \%(246)$ & $16 \%(94)$ & $16 \%(302)$ & $15 \%(1176)$ & $15 \%(1818)$ \\
\hline Steroid use & $80 \%(1461)$ & $80 \%(468)$ & $76 \%(1418)$ & $78 \%(6081)$ & $78 \%(9428)$ \\
\hline Pulmonary infection & $34 \%(628)$ & $29 \%(167)$ & $24 \%(441)$ & $25 \%(1897)$ & $26 \%(3133)$ \\
\hline DCD & $0.9 \%(17)$ & $0.9 \%(5)$ & $0.7 \%(14)$ & $0.6 \%(48)$ & $0.7 \%(84)$ \\
\hline
\end{tabular}

Boldface font suggests characteristics with significant statistical differences between the groups by univariate analysis. $\mathrm{PaO}$, Arterial partial pressure of oxygen; $\mathrm{COD}$, cause of death; $C V A$, cerebrovascular accident; $D C D$, donation after cardiac death.

has always been thought to be highly associated with posttransplant lung function and graft survival has been donor $\mathrm{PaO}_{2}$. There are a few single-center studies demonstrating no adverse effect on graft survival when lungs are used from a donor with a $\mathrm{PaO}_{2}$ less than $300 \mathrm{~mm} \mathrm{Hg.}{ }^{5,17-19}$ These series and the ISHLT LTx consensus group discussion on the establishment of donor $\mathrm{PaO}_{2}$ as a criterion spurred us to investigate the effect of donor $\mathrm{PaO}_{2}$ on graft survival in a large multi-institutional comprehensive national database.

The current series demonstrated that about $20 \%$ of the donors used for LTx in the United States over the past decade had a donor $\mathrm{PaO}_{2}$ of less than $300 \mathrm{~mm} \mathrm{Hg}$ at the time of procurement. This use of donors that did not adhere to the "ideal" $\mathrm{PaO}_{2}$ criterion did not affect early or midterm graft survival. However, if low donor $\mathrm{PaO}_{2}$ were almost exclusively in patients donating to single LTx recipients, then our findings would not be surprising inasmuch as low donor $\mathrm{PaO}_{2}$ could be secondary to single lung disease. The successful use of a single donor lung from donors with low $\mathrm{PaO}_{2}$ and significant contralateral lung disease is widely documented. ${ }^{20}$ However, in the current series the use of donor lungs with a $\mathrm{PaO}_{2}$ of less than $300 \mathrm{~mm} \mathrm{Hg}$ was evenly distributed among single and double LTx recipients. Also, despite $21 \%$ of double LTxs having a donor $\mathrm{PaO}_{2}$ of less than $300 \mathrm{~mm} \mathrm{Hg}, \mathrm{PaO}_{2}$ levels had no effect on graft survival in double LTx. In fact, the recipient characteristics listed in Table 2 demonstrate that patients receiving lungs from a donor with a $\mathrm{PaO}_{2}$ of less than $300 \mathrm{~mm} \mathrm{Hg}$ were more likely $(P<.05)$ to be undergoing a double LTx than a single LTx. Also, the use of donor lungs with a $\mathrm{PaO}_{2}$ of less than $300 \mathrm{~mm} \mathrm{Hg}$ is becoming a more frequent practice over time in that this practice is seen significantly more in the 2005 to 2009 era than in the 2000 to 2004 era. One should also note that recipients of donor lungs with a $\mathrm{PaO}_{2}$ of less than $300 \mathrm{~mm} \mathrm{Hg}$ were more likely to be mechanically ventilated and have interstitial pulmonary fibrosis, which may speak to why centers were willing to accept less than ideal donor lungs. However, the recipients of these lungs were not more likely to be receiving extracorporeal membrane oxygenation or be undergoing retransplantation. The recipients' weight and age were found to be statistically different among the donor $\mathrm{PaO}_{2}$ cohorts, but it would be difficult to see the clinical relevance of recipients being $1 \mathrm{~kg}$ heavier or 1 year older. An analysis of donor characteristics (Table 1) revealed statistical differences in weight and age, but again the clinical relevance of these very small differences is hard to determine. The pattern of differences in

TABLE 2. Recipient characteristics

\begin{tabular}{|c|c|c|c|c|c|}
\hline Donor $\mathrm{PaO}_{2}(\mathrm{~mm} \mathrm{Hg})$ & $<200(\mathrm{n}=1830)$ & $201-300(n=582)$ & $301-400(n=1877)$ & $>400(n=7756)$ & Overall \\
\hline Mean age $(y)$ & $51 \pm 14.6$ & $51 \pm 14.8$ & $52 \pm 14.1$ & $50 \pm 14.8$ & $51 \pm 14.7$ \\
\hline Age $<18$ y & $3.8 \%(70)$ & $3.6 \%(21)$ & $2.8 \%(52)$ & $3.9 \%(301)$ & $3.7 \%(444)$ \\
\hline Weight (kg) & $70 \pm 18.3$ & $70 \pm 18.8$ & $70.3 \pm 18$ & $69 \pm 18.4$ & $69 \pm 18.3$ \\
\hline \#1 Diagnosis: COPD & $30 \%(554)$ & $34 \%(200)$ & $36 \%(667)$ & $33 \%(2581)$ & $33 \%(4002)$ \\
\hline \#2 Diagnosis: IPF & $29 \%(524)$ & $27 \%(157)$ & $26 \%(484)$ & $25 \%(1896)$ & $25 \%(3061)$ \\
\hline \multicolumn{6}{|l|}{ Era } \\
\hline 2000-2004 & $18 \%(332)$ & $30 \%(173)$ & $42 \%(784)$ & $48 \%(3702)$ & $41 \%(4991)$ \\
\hline 2005-2009 & $82 \%(1498)$ & $70 \%(409)$ & $58 \%(1093)$ & $52 \%(4054)$ & $59 \%(7054)$ \\
\hline Double lung & $61 \%(1118)$ & $62 \%(359)$ & $55 \%(1036)$ & $58 \%(4513)$ & $58 \%(7026)$ \\
\hline Re-transplants & $4 \%(77)$ & $4 \%(23)$ & $4 \%(74)$ & $4 \%(289)$ & $4 \%(463)$ \\
\hline Ventilator dependant & $6 \%(105)$ & $6 \%(33)$ & $5 \%(85)$ & $4 \%(309)$ & $4.4 \%(532)$ \\
\hline ECMO & $1 \%(15)$ & $1 \%(8)$ & $1 \%(11)$ & $1 \%(63)$ & $0.8 \%(97)$ \\
\hline
\end{tabular}

Boldface font suggests characteristics with significant statistical differences between the groups by univariate analysis. $\mathrm{PaO}$, Arterial partial pressure of oxygen; $\mathrm{COPD}$, chronic obstructive pulmonary disease; $I P F$, interstitial pulmonary fibrosis; ECMO, extracorporeal membrane oxygenation. 

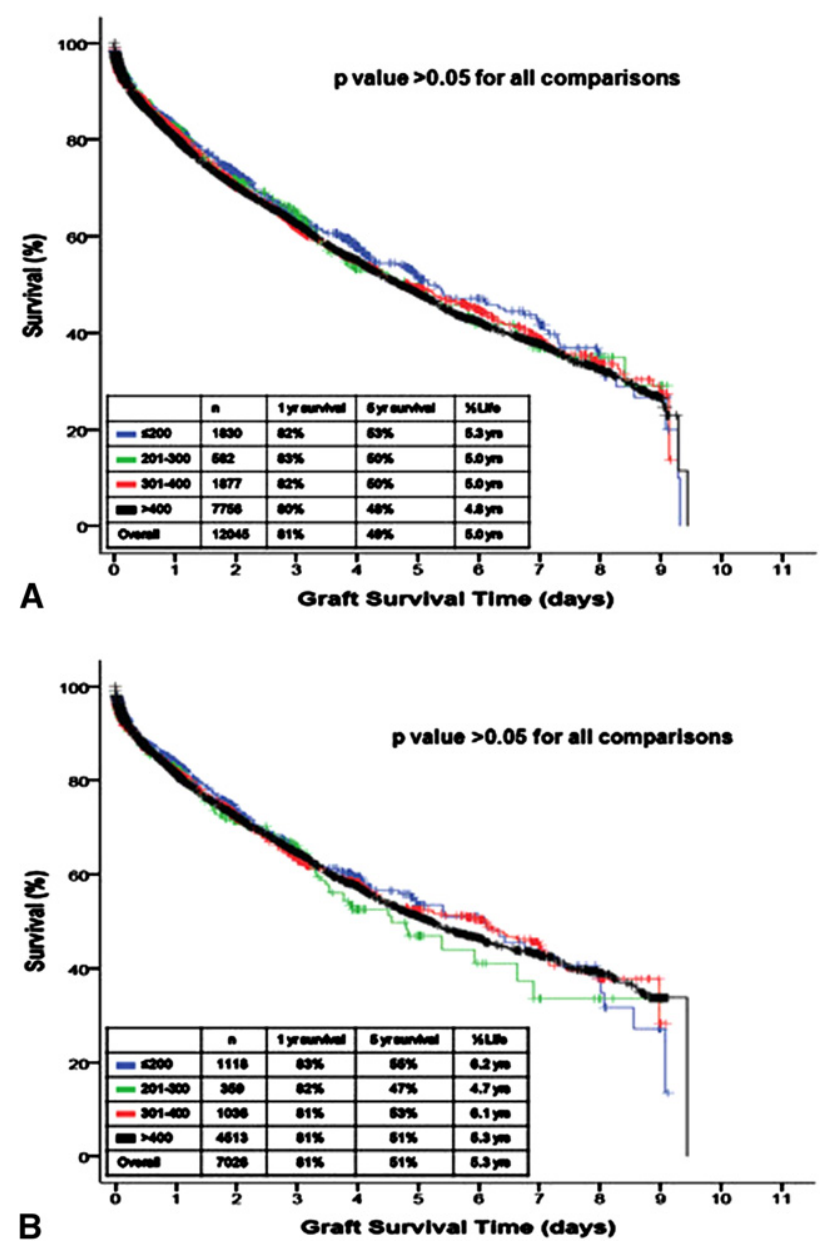

FIGURE 1. Kaplan-Meier survival curve for overall lung transplantation (A) and double lung transplantation (B). LTx, Lung transplantation.

cause of death in the different donor $\mathrm{PaO}_{2}$ cohorts is not consistent enough to draw conclusions between those donors with a $\mathrm{PaO}_{2}$ of less than $300 \mathrm{~mm} \mathrm{Hg}$ as a group (cohorts $<200 \mathrm{~mm} \mathrm{Hg}$ and 201-300 mm Hg) and those with ideal donor $\mathrm{PaO}_{2}$ (cohorts 301-400 mm Hg and $>400 \mathrm{~mm} \mathrm{Hg}$ ). Interestingly, it does appear that both donor cohorts with a $\mathrm{PaO}_{2}$ of less than 300 were more likely to have a pulmonary infection and to have been given steroids than those donors with $\mathrm{PaO}_{2}$ of more than $300 \mathrm{~mm} \mathrm{Hg}$. The centers accepting these less than "ideal" donor lungs may have believed that the infections were the cause of the decreased $\mathrm{PaO}_{2}$ and that the infections could be treated effectively after transplant. Therefore, it may be that the increased use of donor lungs with low $\mathrm{PaO}_{2} \mathrm{~S}$ is secondary to centers becoming more confident that they can successfully treat donor lung infections after transplant.

The retrospective nature of the study, the lack of granularity of the database, and the incomplete population of certain data fields were all limitations to the study. Another important limitation is that the timing of when the donor $\mathrm{PaO}_{2}$ value was recorded in the database is not known.
TABLE 3. Multivariate analysis of 21 donor characteristics association with graft survival

\begin{tabular}{|c|c|c|c|c|}
\hline & \multirow[b]{2}{*}{ Significance } & \multirow{2}{*}{$\begin{array}{c}\text { Hazard } \\
\text { ratio }\end{array}$} & \multicolumn{2}{|c|}{$\begin{array}{c}95.0 \% \text { CI } \\
\text { for } \operatorname{Exp}(B)\end{array}$} \\
\hline & & & Lower & Upper \\
\hline ABO blood type & .060 & 1.003 & 1.000 & 1.006 \\
\hline Donor age & .589 & .954 & .803 & 1.133 \\
\hline Pulmonary infection & .818 & 1.021 & .854 & 1.222 \\
\hline Donor cause of death & .487 & .847 & .531 & 1.353 \\
\hline Smoking history & .260 & 1.465 & .753 & 2.848 \\
\hline History of cocaine abuse & .540 & .900 & .644 & 1.259 \\
\hline IV drug abuse & .373 & 1.515 & .608 & 3.777 \\
\hline Donor ethnicity & .083 & .275 & .064 & 1.186 \\
\hline History of extracranial cancer & .763 & 1.200 & .366 & 3.930 \\
\hline Alcohol abuse & .382 & 1.349 & .690 & 2.636 \\
\hline History of cancer & .436 & .530 & .107 & 2.617 \\
\hline Hypertension & .018 & 1.792 & 1.105 & 2.904 \\
\hline Insulin-dependent diabetes & .559 & 1.363 & .483 & 3.847 \\
\hline $\begin{array}{l}\text { History of myocardial } \\
\text { infarction }\end{array}$ & .974 & .989 & .515 & 1.901 \\
\hline History of intracranial cancer & .133 & .629 & .344 & 1.151 \\
\hline Non-heart beating donor & .797 & 3.117 & .000 & 0.115 \\
\hline Steroid use & .043 & 1.765 & 1.018 & 3.060 \\
\hline Creatinine $>2$ & .994 & 1.001 & .865 & 1.158 \\
\hline LVEF <30\% & .892 & .990 & .863 & 1.137 \\
\hline Donor $\mathrm{PaO}_{2}$ & .526 & .971 & .888 & 1.062 \\
\hline Donor weight & .024 & .998 & .996 & 1.000 \\
\hline
\end{tabular}

Boldface font suggests characteristics with significant statistical differences between the groups by univariate analysis. $C I$, Confidence interval; $I V$, intravenous; $L V E F$, left ventricular ejection fraction; $\mathrm{PaO}_{2}$, arterial partial pressure of oxygen.

The donor $\mathrm{PaO}_{2}$ data available only represent a moment in time and do not show trends in $\mathrm{PaO}_{2}$ or a response to a low $\mathrm{PaO}_{2}$. Therefore, the effect of measures taken to optimize a donor lung with a recorded $\mathrm{PaO}_{2}$ of less than 300 $\mathrm{mm} \mathrm{Hg}$ would not be captured in the database.

The current study suggests that despite a low donor $\mathrm{PaO}_{2}$, if the other donor characteristics indicate that the lungs are acceptable then those lungs should be considered for transplantation. This is in agreement with the work of Reyes and associates ${ }^{17}$ which analyzed variances from current donor

TABLE 4. Donor acceptability criteria

\section{Currently accepted "ideal" donor}

Age $<55$ y

ABO compatibility

Clear chest radiograph

$\mathrm{PaO}_{2}>300$ on $\mathrm{FiO}_{2}=1.0$, PEEP $5 \mathrm{~cm} \mathrm{H}_{2} \mathrm{O}$

Tobacco history $<20$ pack-years

Absence of chest trauma

No evidence of aspiration/sepsis

No prior cardiopulmonary surgery

Sputum Gram stain—absence of organisms

Absence of purulent secretions at bronchoscopy

$\mathrm{PaO}_{2}$, Arterial partial pressure of oxygen; $\mathrm{FiO}_{2}$, fraction of inspired oxygen; $\mathrm{PEEP}$, positive end-expiratory pressure. 
guidelines and found them to be frequent and have minor to no impact on outcomes. Ideally, the findings of these series may give clinicians more confidence when deciding to accept donor lungs that are not "ideal." Interestingly, as documented in this series, this decision to use donor lungs with a $\mathrm{PaO}_{2}$ of less than $300 \mathrm{~mm} \mathrm{Hg}$ is being made already in nearly a fifth of all LTxs being performed in the United States. The decision to use lungs with less than ideal characteristics will only become easier in the next few years as ex vivo lung perfusion will allow these "marginal" donor lungs to be reassessed and optimized before implantation.

Donor $\mathrm{PaO}_{2}$ does not appear to affect pulmonary graft survival. Therefore, this result appears to provide an opportunity to substantially increase the donor lung pool and begin to rebalance the donor-recipient imbalance. We are not suggesting that donor $\mathrm{PaO}_{2}$ is not important when assessing potential lung donors, but its level of importance in regard to other criteria appears less than previously believed.

\section{References}

1. Gabbay E, Williams TJ, Griffiths AP, Macfarlane LM, Kotsimbos TC, Esmore DS, et al. Maximizing the utilization of donor organs offered for lung transplantation. Am J Respir Crit Care Med. 1999;160:265-71.

2. Straznicka M, Follette DM, Eisner MD, Roberts PF, Menza RL, Babcock WD. Aggressive management of lung donors classified as unacceptable: excellent recipient survival one year after transplantation. J Thorac Cardiovasc Surg. 2002; 124:250-8.

3. Pierre AF, Sekine Y, Hutcheon MA, Waddell TK, Keshavjee SH. Marginal donor lungs: a reassessment. J Thorac Cardiovasc Surg. 2002;123:421-8.

4. Bhorade SM, Vigneswaran W, McCabe MA, Garrity ER. Liberalization of donor criteria may expand the donor pool without adverse consequence in lung transplantation. J Heart Lung Transplant. 2000;19:1199-204.

5. Shumway SJ, Hertz MI, Petty MG, Bolman RM. Liberalization of donor criteria in lung and heart-lung transplantation. Ann Thorac Surg. 1994;57:92-5.

6. McKellar SH, Durham LA, Scott JP, Cassivi SD. Successful lung transplant from donor after cardiac death: a potential solution to shortage of thoracic organs. Mayo Clin Proc. 2010;85:150-2.

7. Frost AE. Donor criteria and evaluation. Clin Chest Med. 1997;18:231-7.

8. Orens JB, Boehler A, Perrot M, Estenne M, Glanville AR, Keshavjee S, et al. A review of lung transplant donor acceptability criteria. J Heart Lung Transplant. 2003;22:1183-200.

9. Harjula A, Baldwin JC, Starnes VA, Stinson EB, Oyer PE, Jamieson SW, et al. Proper donor selection for heart-lung transplantation: the Stanford experience. J Thorac Cardiovasc Surg. 1987;94:874-80.

10. US Department of Health and Human Services. Health Resources and Services Administration OPTN Organ Procurement and Transplantation Network Web site. http://optn.transplant.hrsa.gov/latestData/rptData.asp. Accessed April 2011.

11. Tuttle-Newhall JE, Krishnan SM, Levy MF, McBride V, Orlowski JP, Sung RS. Organ donation and utilization in the United States: 1998-2007. Am J Transplant. 2009;9:879-93.

12. Mason DP, Murthy SC, Gonzalez-Stawinski GV, Budev MM, Mehta AC, McNeill AM, et al. Early experience with lung transplantation using donors after cardiac death. J Heart Lung Transplant. 2008;27:561-3.

13. Mason DP, Thuita L, Alster JM, Murphy SC, Budev MM, Mehta AC, et al. Should lung transplantation be performed using donation after cardiac death? The United States experience. J Thorac Cardiovasc Surg. 2008;136:1061-6.

14. Snell GI, Levvey BJ, Oto T, McEgan R, Pilcher D, Davies A, et al. Early lung transplantation success utilizing controlled donation after cardiac death donors. Am J Transplant. 2008;8:1282-9.

15. Cypel M, Yeung JC, Keshavjee S. Novel approaches to expanding the lung donor pool: donation after cardiac death and ex-vivo conditioning. Clin Chest Med. 2011;32:233-44.

16. Cypel M, Yeung JC, Liu M, Anraku M, Chen F, Karolak W, et al. Normothermic ex vivo lung perfusion in clinical lung transplantation. N Engl J Med. 2011;364: 1431-40.
17. Reyes KG, Mason DP, Thuita L, Nowicki ER, Murthy SC, Pettersson GB, et al. Guidelines for donor lung selection: time for revision? Ann Thorac Surg. 2010; 89:1756-65

18. Sundaresan S, Semenkovich J, Ochoa L, Richardson G, Trulock EP, Cooper JD, et al. Successful outcome of lung transplantation is not compromised by the use of marginal lungs. J Thorac Cardivasc Surg. 1995;109:1075-9.

19. Lardinois D, Banysch M, Korom S, Hillinger S, Rousson V, Boehler A, et al. Extended donor lungs: eleven years experience in a consecutive series. Eur J Cardiothorac Surg. 2005;27:762-7.

20. Puskas JD, Winton TL, Miller DJ, Scavuzzo M, Patterson GA. Unilateral donor lung dysfunction does not preclude successful contralateral single lung transplantation. J Thorac Cardiovasc Surg. 1992;103:1015-7.

\section{Discussion}

Dr Thomas K. Waddell (Toronto, Ontario, Canada). Dr Morales, thank you for an interesting analysis and for sending the paper in advance.

The subject of appropriate criteria for acceptance of the donor lung has been extensively discussed, and there is a consensus that many usable organs are ultimately rejected for poorly evaluated criteria. You are to be congratulated for revisiting this issue.

Increasingly sophisticated analyses have been brought to bear, and this is one of my major concerns regarding your paper. Two approaches were taken in this analysis. One was to divide the cohort into 4 groups, and there was no difference in survival using a log-rank analysis. In the second analysis you took all 21 donor variables that were available and put them into a multivariable analysis. Once again, donor $\mathrm{PaO}_{2}$ was not statistically significant.

Why did you not deal with the subject of recipient covariants? You did show in the first analysis that there were no major differences. However, I would refer you to a very interesting analysis by Reyes from the Cleveland Clinic published in The Annals of Thoracic Surgery in June of 2010 that took essentially the same data set from UNOS and came to very different conclusions. In particular, Reyes' group showed that $\mathrm{PaO}_{2}$ of less than $230 \mathrm{~mm} \mathrm{Hg}$ was a problem. Even more emphatically, there was an analysis by Hennessy from the University of Virginia group that took the UNOS data from an even larger data set and found that there was in fact an adverse effect of high $\mathrm{PaO}_{2}$. Thus we have 3 analyses from the same data source that have come to 3 different conclusions. In particular, yours is one that does not have any correction for recipient characteristics, and I wonder if you could address why not.

Dr Morales. The fact that 3 different conclusions have been derived from the same database will demonstrate that it is probably unclear whether donor $\mathrm{PaO}_{2}$ really does have an effect on graft survival. Three different institutions have looked at it and have not come up with a consistent finding. We thought that we accounted for recipient characteristics with the fact that when we analyzed them in subgroups, they really did not differ clinically. These things did not really differ by age or by weight, except for the fact that more double LTxs were done with donors who had a $\mathrm{PaO}_{2}$ that was lower. Thus I think that we did look at recipient characteristics in our different subgroups.

Dr Waddell. Some of the recipient characteristics that you looked at were not actually the ones that are most tightly linked to outcome, and that would be a limitation.

My second question concerns what I consider to be one of the more interesting findings, and you did not really remark on it. The statistically significant donor variable that was associated 
with poor outcome was in fact steroid use. You could make the similar argument in your introduction that steroid use in the donor was introduced with very little evidence base, and I found it interesting that the use of steroids was associated with a hazard ratio of 1.7 , meaning quite bad for long-term outcome. Do you want to speculate on why that might be? Do you think we need to revisit the use of steroids? Do you think we should do a randomized trial to evaluate it?

Dr Morales. Thank you for your comments.

I did not put that in the presentation, but it is true that steroid use did come out in the analysis. My transplant program thought long and hard about why that would be, and we were not quite sure, especially since in the ex vivo protocols, we are now using steroids during that time to help recover the lung.

Dr Bryan F. Meyers (St Louis, Mo). Right now I think LTx is a luxurious therapy. With the amount of benefit it provides, it is very expensive, both to do it and to maintain the patients afterward. Future analysis on something like this has to look at the efficiency of the procedure as well as the early outcomes of survival or nonsurvival. It we take perfect lungs and use them, we are going to get a certain baseline outcome for a baseline expenditure. As we begin using more risky lungs, we will encounter a more complex and more expensive perioperative course. The likelihood of bypass and extracorporeal membrane oxygenation will increase. The risk of acute retransplantation will increase, and the longer-term benefit will be diminished as well. I think that your first cut on this is useful and thought-provoking. However, we need to get beyond just the most elemental evaluation of something like the donor $\mathrm{PaO}_{2}$ and look at the incremental cost and the incremental benefit that we would get by extending the use of donors that are less than optimal.

Dr Morales. Thank you for your comments. I agree. Things like the UNOS database, the Nationwide Input Sample database, and other administrative databases are problematic in that they only supply short-term follow-up. We are starting, especially with The Society of Thoracic Surgeons database, to think of linking these to longer-term follow-ups, such as the Social Security Death Master File or the National Death Index, from which long-term mortality can be obtained. If something like the UNOS database could be connected it to the Social Security Death Master File, then the long-term effect of donor $\mathrm{PaO}_{2}$ on these grafts could be determined. I think that should be a way to empower most of our surgical databases, which are always limited by the fact that we do not have long-term follow-up.

Dr Marcelo Cypel (Toronto, Ontario, Canada). I have 1 comment and 2 quick questions.

One of the major problems with these data is that the $\mathrm{PaO}_{2}$ was collected before you opened the chest and recruited the lungs. I would imagine with the $20 \%$, it would be a much smaller number that would actually have $\mathrm{PaO}_{2}$ less than 300 when you have optimized conditions.

My first question is this: what do you mean by graft survival here, and why didn't you use the ISHLT primary graft dysfunction scores? I am not sure what graft survival means in days, as you showed there.

The second question is whether you see a correlation of the implementation of the lung allocation score with the increased numbers of lungs being assessed with $\mathrm{PaO}_{2}$ s less than $300 \mathrm{~mm} \mathrm{Hg}$.
Dr Morales. To answer your questions, we did not look at the lung allocation score. By graft survival, we mean survival either to retransplantation or to death. I do realize, and I mentioned this

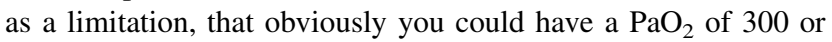
250 , then take them to the operating room, recruit the lungs, and then find that the $\mathrm{PaO}_{2}$ is 400 . But I think it is surprising. If we polled everyone before we gave this presentation and asked what percentage of people in the UNOS database has a $\mathrm{PaO}_{2}$ less than 300 , I'm not sure many people would have said $20 \%$. I think it just brings up the fact that we have all grown up talking about $\mathrm{PaO}_{2}$ S over 300 , but that level is not really established in any real data, and so I think it is thought-provoking. Again, I also think when you get a donor call and the first $\mathrm{PaO}_{2}$ is $200 \mathrm{~mm} \mathrm{Hg}$ on $100 \% \mathrm{FiO}_{2}$, unless your recipient is very sick, many people would not think these lungs were acceptable. Perhaps this study will make people think a little bit more about whether such lungs might be usable.

Dr Ankit Bharat (St Louis, Mo). Thank you for an interesting presentation.

One of my concerns is that you demonstrated that there is no difference in the long-term graft survival, and I presume this is looking at chronic rejection. We know chronic rejection has a multifactorial pathology and is affected by multiple other variables. I was wondering whether you looked at the short-term or the acute events, such as development of primary graft dysfunction, sepsis, and things like 30-day mortality in these patients and found any effects in patients who had low $\mathrm{PaO}_{2} \mathrm{~S}$ compared with those who had lungs with a better $\mathrm{PaO}_{2}$. My second question is, if there were such differences, is it possible that the differences in treatment between these 2 groups of patients in the short term affected their long-term survival and development of chronic rejection?

Dr Morales. The 2 things that we did look at were acute rejection in the hospital and length of stay, neither of which was statistically different between the 2 groups. You are right. Perhaps if you took a set of lungs with a $\mathrm{PaO}_{2}$ that was 250 , you would take perhaps better care of those lungs postoperatively. Obviously, I cannot comment on that through a database.

Dr Joel D. Cooper (Philadelphia, Pa). I rise to discuss a point in history. I enjoyed your paper very much.

The $300 \mathrm{~mm} \mathrm{Hg}$ level is something that we inherited as well, in the early days. I must say that I learned a great deal from the Stanford group about heart-lung transplants. When we began getting into heart-lung and lung transplants, we visited there and tried to learn as much as we could from them. Perhaps that is where it arose. I would also point out that in the early days, we and others did everything possible to eliminate any adverse effects of donor lung ischemia. We only used donors from our own city, we only used very short ischemic times, and, yes, we only used donors in whom the $\mathrm{PaO}_{2}$ was greater than $300 \mathrm{~mm} \mathrm{Hg}$, because at least that is what I was advised. Obviously, as a procedure matures, you are willing to take more risk, you do not believe that the whole future of LTx rests in having every case successful, and you are willing to use more marginal donors. I do not know where it arose, and it was just an arbitrary standard, which seemed to be a very high standard. We wanted to reduce as much as possible any adverse factors that might affect the outcome in those early days.

Dr Shaf Keshavjee (Toronto, Ontario, Canada). There is a point, Dr Morales, that still concerns me. There have been at least 2 previous major analyses of about 10,000 patients, plus or minus 
1000 , looking at this fact. As you and Dr Waddell mentioned, they came to different conclusions. That does not tell me that the $\mathrm{PaO}_{2}$ is not as important as we used to think. That may well be true, but it speaks more to errors that we could make in throwing out a blanket statement, like: “Don't worry about $\mathrm{PaO}_{2}$ because it didn't come out as a significant factor." I think it speaks also to the quality of the data. What you have shown again is that lungs were used successfully that at some point in the donor journey got a low $\mathrm{PaO}_{2}$ recorded by some coordinator in the middle of the night somewhere in the United States. That does not necessarily tell you that $\mathrm{PaO}_{2}$ is not important. Again, it may not be as important, and we are learning more about that and studying it, but I would not think that that is a valid statement to make from the data that you were working with.

Dr Morales. As my conclusions stated, I am not actually stating that donor $\mathrm{PaO}_{2}$ is not important, but how critical it is for predicting graft survival especially at the level of $300 \mathrm{~mm} \mathrm{Hg}$ is unclear. Through the data that we analyzed, this is what we can conclude. Again, I do not believe that we should not be concerned about the donor $\mathrm{PaO}_{2}$, but its level of importance or the level of donor $\mathrm{PaO}_{2}$ that is acceptable is something that we need to think about and question. 